\title{
TU/e emonownen

\section{Estimation of instantaneous flow from the indicator-dilution curve after bolus injection of indicator}

\section{Citation for published version (APA):}

van Reth, E. A., Pluijm, M. J. F. P., Steenhoven, van, A. A., Poulis, J. A., \& Versprille, A. (1987). Estimation of instantaneous flow from the indicator-dilution curve after bolus injection of indicator. Medical and Biological Engineering and Computing, 25(1), 51-56. https://doi.org/10.1007/BF02442820

DOI:

10.1007/BF02442820

Document status and date:

Published: 01/01/1987

\section{Document Version:}

Publisher's PDF, also known as Version of Record (includes final page, issue and volume numbers)

\section{Please check the document version of this publication:}

- A submitted manuscript is the version of the article upon submission and before peer-review. There can be important differences between the submitted version and the official published version of record. People interested in the research are advised to contact the author for the final version of the publication, or visit the $\mathrm{DOI}$ to the publisher's website.

- The final author version and the galley proof are versions of the publication after peer review.

- The final published version features the final layout of the paper including the volume, issue and page numbers.

Link to publication

\section{General rights}

Copyright and moral rights for the publications made accessible in the public portal are retained by the authors and/or other copyright owners and it is a condition of accessing publications that users recognise and abide by the legal requirements associated with these rights.

- Users may download and print one copy of any publication from the public portal for the purpose of private study or research.

- You may not further distribute the material or use it for any profit-making activity or commercial gain

- You may freely distribute the URL identifying the publication in the public portal.

If the publication is distributed under the terms of Article 25fa of the Dutch Copyright Act, indicated by the "Taverne" license above, please follow below link for the End User Agreement:

www.tue.nl/taverne

Take down policy

If you believe that this document breaches copyright please contact us at:

openaccess@tue.nl

providing details and we will investigate your claim. 


\title{
Estimation of instantaneous flow from the indicator-dilution curve after bolus injection of indicator
}

\author{
E. A. von Reth \\ Application Department, Medical Systens Division, Philips International BV, PO Box $218,5600 \mathrm{MD}$
} Eindhoven. The Netherlands

M. J. F.P. Pluym

A. A. van Steenhoven

J. Poulis

Departments of Physics and Mechanical Engineering. Eindhoven University of Technology Den Dolech 2, PO Box 513,5600 MB Eindhoven, The Netherlands

\section{A. Versprille}

Pathophysiological Laboratory, Department of Pulmonary Diseases, Erasmus University Burgemeester Oudlaan 50, PO Box 1738,3000 DR Rotterdam, The Netherlands

Alostract - The indicator-difution technique is commonly used to determine mean flow estimates. The estimation of instantaneous flow from the shape of an indicator dilution curve is the objective of this study. Based on a mixing chamber approach to the flow system, a mathematical relationship is derived to reconstruct momemtary flow from an indicator difution curve. This relationship is verified in a model setup beth with only constant flow and with a sinusoidal flow variation superimposed. This method proved to give good flow estimates for limited values of flow parameters. Also, some preliminary experiments were performed in a pulsating flow system simulating heart action. The results were promising although the method proved to be very sensitive to baseline offset.

Keywords Indicator dilution, Instantaneous flow, Mixing chamber model

Med. \& Biol. Eng, \& Comput., $1987,25,51-56$

\section{Introduction}

THE INDICATOR-DILUTION technique is often used in clinical and physiological situations to determine cardiac output estimates (BRANTHWAITE and BRADLEY, 1968; SilOve et al., 1971). Owing to the nonstationary character of the flow, caused by heart pulsations and ventilation effects, large errors can occur in cardiac output determination when using the technique in these applications. This was concluded from model experiments, theoretical studies (CrOPP and Burton, 1966; BASSINGTHWAighte et al., 1970; vON RETH et al., 1983) and in vivo experiments (JANSEN et al., 1979; 1981; SNYDER and POWNER, 1982).

Solutions were proposed by these authors to correct for the mentioned nonstationary effects in the estimation of the mean flow value. The effects of nonstationary flow can be recognised in the shape of the indicator-dilution curve. It is the purpose of the present study to investigate whether information about the instantaneous flow as well as a mean value determination can be obtained from an indicator-dilution curve. Both low-frequency variations (ventilation) and high-frequency variations are aimed at. Until now, determination of variable flow phenomena from indicator-dilution curves has been restricted mainly

First received 9th February 1985 and in final form 9th April 1986

(C) IFMBE: 1987 to beat-to-beat estimates of ventricular outputs and volumes (JARLOV and MYGIND, 1979; JARLOV and LARSEN, 1981). CROPP and BURTON (1966) estimated the instantaneous value of the flow from the concentration recordings after a continuous infusion of indicator. They concluded that the reciprocal of the measured indicator concentration plotted against time gives an acceptable representation of instantaneous flow when the mixing is good and the distance between injection and sampling points is small. Their analysis is not, however, applicable to the bolus-injection method.

We studied the estimation of instantaneous flow with the bolus-injection method by representing the mixing system by ideal mixing chambers in series. The usefulness of this model was tested by analysis of curves either theoretically derived or measured in a hydrodynamical setup.

\section{Theory}

Modelling indicator transport in a flow system by means of a series of ideal mixing chambers has been described by several investigators (SCHLOSSMACHER et al., 1967; VALENTINUZZI et al., 1972; VON RETH and BOGAARD, 1983; VON RETH, 1984). The flow as a function of time can be derived from the differential equations describing the 
mixing of indicator in a system of $N$ equal ideal mixing chambers in series after a bolus injection of indicator:

$$
V \frac{d C_{k}(t)}{d t}=-F(t)\left(C_{k}(t)-C_{k-1}(t)\right) \quad k=1 \ldots N
$$

where $V$ is the volume of each mixing chamber, $C_{k}$ is the concentration behind the $k$ th chamber and $F(t)$ is the flow function.

This set of equations can be solved for a known flow function and initial conditions to describe the indicatordilution curve (SCHLOSSMACHER et al., 1967).

The other way around, it is also possible to derive the flow function $F(t)$ when we start from a measured $C_{N}(t)$ curve and known initial conditions.

For a bolus injection of indicator ( $\delta$-function) in a flow with a zero indicator concentration the initial conditions read:

$$
C_{1}(0)=\frac{m_{i n j}}{V} \quad \text { and } \quad C_{0}(t)=0
$$

where $m_{i n j}$ is the amount of indicator injected.

In our analysis we take the quotient of the first and the last differential equations from eqn. 1.

$$
\frac{d C_{N}(t) / d t}{d C_{1}(t) / d t}=\frac{C_{N}(t)-C_{N-1}(t)}{C_{1}(t)}
$$

when

$$
\frac{d C_{1}(t)}{d t} \neq 0 \quad \text { and } \quad C_{1}(t) \neq 0 .
$$

Eliminating the time variable gives

$$
\frac{d C_{N}\left(C_{1}\right)}{d C_{1}}=\frac{C_{N}\left(C_{1}\right)-C_{N-1}\left(C_{1}\right)}{C_{1}}
$$

which is a standard first-order differential equation. The solution of eqn. 4 , taking eqn. 2 into account reads:

$$
C_{N}\left(C_{1}\right)=\frac{1}{(N-1) !} C_{1}\left\{-\ln \left(\frac{C_{1}}{m_{i n j} / V}\right)\right\}^{N-1}
$$

To illustrate the use of eqn. 5 we consider the situation with a constant flow $F_{c}$, where the (virtual) indicatordilution curve $C_{1}(t)$ is given by

$$
C_{1}(t)=\frac{m_{i n j}}{V} \exp \left(-\frac{F_{c}}{V} t\right)
$$

Using eqn. 6 in eqn. 5 gives, for constant flow,

$$
C_{N}(t)=\frac{m_{i n j}}{V} \frac{1}{(N-1) !}\left(\frac{F_{c}}{V} t\right)^{N-1} \exp \left(-\frac{F_{c}}{V} t\right)
$$

an equation also found by SCHLOSSMACHER et al. (1967), among others.

Flow $F(t)$ can be derived from the set of differential equations of eqn. 1 by rewriting the equation for the first compartment:

$$
F(t)=-V \frac{d C_{1}(t) / d t}{C_{1}(t)}
$$

Both $C_{1}(t)$ and $d C_{1}(t) / d t$ can be calculated from the measured $C_{N}(t)$ and $d C_{N}(t) / d t$ curves using eqn. 5. This leads to

$$
F(t)=-V \frac{d C_{N}(t) / d t}{C_{N}(t)} K(t)
$$

where

$$
K(t)=\left\{1+\left\{\frac{N-1}{\ln \left(\frac{C_{1}(t)}{m_{i n j} / V}\right)}\right\}\right\}^{-1}
$$

When discussing the measurements, we will use the function $Q(t)$ which is determined from

$$
Q(t)=K(t) \frac{d C_{N}(t) / d t}{C_{N}(t)}
$$

This function is related to the flow by

$$
F(t)=-V Q(t)
$$

\section{Method}

\subsection{Experimental setup}

The procedure described was tested experimentally in a flow system able to produce a constant flow and sinusoidal modulated flow. The flow system used is described in more detail elsewhere (VON RETH et al., 1983; vON RETH, 1984); here only a synopsis will be given. The system consists basically of two pumps (a constant-flow pump and a plunger pump), a mixing compartment partially filled with glass beads to ensure good indicator mixing, and a tube system. The fluid used was a salt solution in water $(0.1 \mathrm{~g} \%)$. Just before the mixing compartment, injection of a small amount $(1 \mathrm{ml})$ of $0.5 \mathrm{~g} \%$ salt solution is made. Behind the mixing region, the conductivity was measured using an electrode formed by two stainless-steel rings. The mixing system was characterised by fitting an $N$ compartment function to a curve, measured with constant flow following the procedure described in vON RETH $e t$ al. (1983) and voN RETr (1984), resulting in an $N$-value and a time constant best describing the mixing system.

By the choice of suitable mixing parts (mixing volumes of varying shape, glass beads, tubes), the system could be varied from a system best described as a single mixing chamber to one best described as a series of $N$ compartments $(2<N<6)$. Simultaneously with the conductivity against time curves, the flow was measured directly with an electromagnetical flowmeter. The indicator injection was pneumatically driven and computer controlled. Under constant flow conditions $\left(F(t)=F_{c}\right)$ the reproducibility of measurements and flow analyses was checked. For several values of constant flow, the estimated flow was assessed by comparing the values measured directly and estimations of the flow using eqn. 11.

The sinusoidally varying flow is defined by

$$
F(t)=F_{m}\left\{1+A \sin \left(\omega t+\phi_{i n j}\right)\right\}
$$

where $F_{m}$ is the mean flow, $A$ the relative amplitude of the variation, $\omega$ the frequency of the variation and $\phi_{i n j}$ the phase at the moment of injection. With eqn. 12 a function $Q(t)$ is expected that reads:

$$
Q(t)=Q_{m}\left\{1+A_{q} \sin \left(\omega_{q} t+\phi_{q}\right)\right\}
$$

For these flows, experimental indicator-dilution curves were analysed for several values of $F_{m}, A$ and $\omega$. The value of $Q(t)$ was calculated from the measured $C(t)$ curves using eqn. 11. The function defined by eqn. 14 was fitted to the measured $Q(t)$ curve by adapting the parameters $A_{q}, \phi_{q}$, $\omega_{q}$ and $Q_{m}$. These parameters were compared with the corresponding parameters of the $F(t)$ function. In all the situations studied, the values of $\omega_{q}$ and $\phi_{q}$ were equal to $\omega$ and $\phi_{i n j}$ within the accuracy of measurement. The values of 
$Q_{m} / F_{m}$ and $A_{q} / A$ were measured as a function of the variable $F(t)$ parameters. The experiments in the onecompartment system were performed for two different volumes of the mixing chamber $(107.6$ and $139.0 \mathrm{ml})$.

Finally, some introductory experiments were performed in a pulsating-flow setup, which simulates heart action modulated by respiratory effects. This model consists of an electrically controlled plunger pump, a compliant tube as main blood vessel and an adjustable capillary resistance connected to a buffer volume; for an extensive description we refer to vON RETH (1984). Fitting the indicator-dilution curve measured in unmodulated flow yields a description of the model as a three-compartment system. In the experiments, the indicator-dilution curve was analysed and the resulting $Q(t)$ function was compared with the flow function measured directly.

\subsection{Data processing}

According to eqns. 9 and 10 , the first derivative of the measured indicator-dilution curve has to be determined to estimate the instantaneous flow. During the analysis, the indicator-concentration signal was filtered by a low-pass filter (Krohn-Hite 3341) before being led to an analogue differentiator. A low-pass filter was inserted to eliminate the disturbances evoked by the differentiator. In a branch parallel to the differentiator, the concentration signal was led through an identical filter to compensate for the time
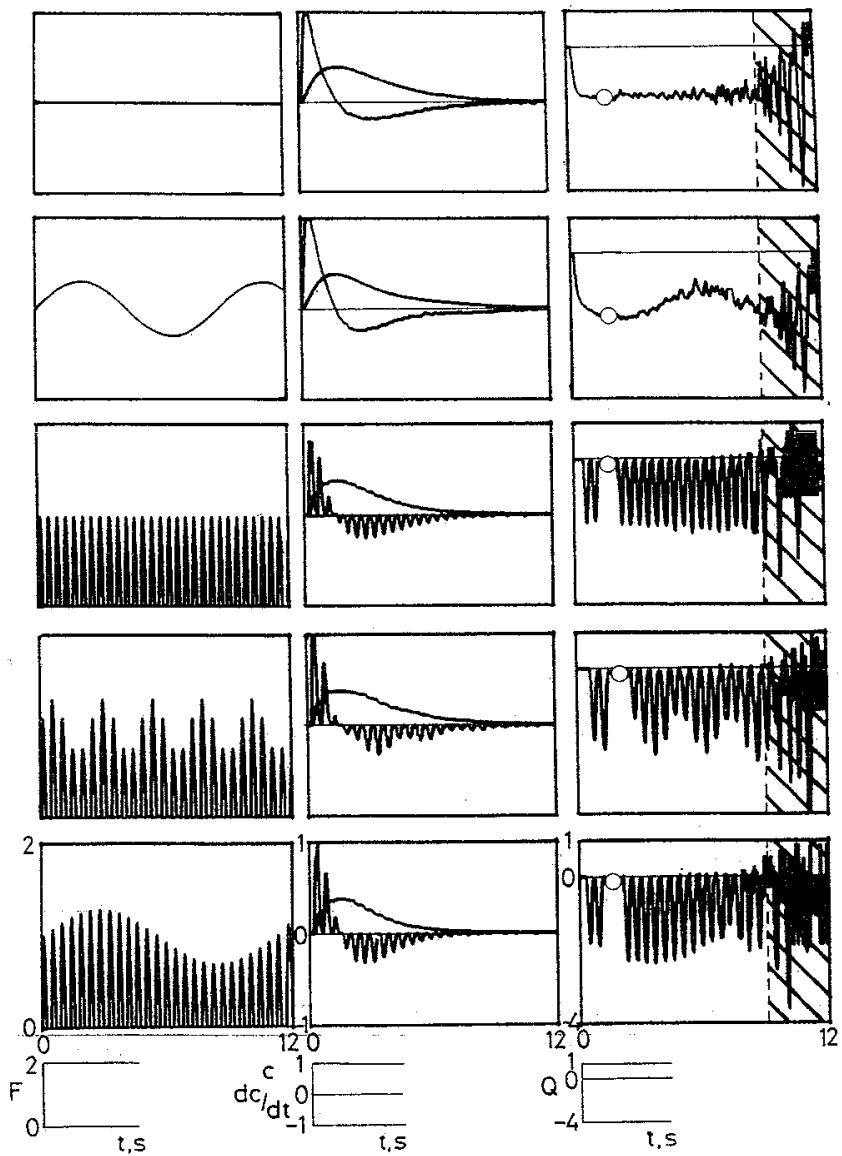

Fig. 1 Testing the analysis with theoretically derived $C(t)$ curves for various flow situations in a two-compartment model. The graphs on the left show the five different input flow functions, the graphs in the middle present the calculated $C(t)$ curves and their derivatives via analogue differentiation. The right-hand graphs show the $Q(t)$ functions determined by eqn. 11. According to eqn. $12 F(t) \propto-Q(t)$. The shaded area and the circle in the $Q(t)$ plots indicate areas where the analysis fails delay in the first filter. A computer (DEC/LSI-11) sampled the concentration signal and its derivative with a sampling frequency of $20 \mathrm{~Hz}$. The virtual indicator-dilution curve after the first mixing compartment $C_{1}(t)$ was determined by solving eqn. 5 numerically. With eqns. 10 and $11, Q(t)$ was determined as a function of time. The function $Q(t)$ was compared with the flow function $F(t)$, measured electromagnetically and also sampled at $20 \mathrm{~Hz}$.

\section{Results}

\subsection{Testing with theoretical curves}

To check the veracity of eqn. 9 and the signal processing procedure, the analysis was performed on curves $C_{N}(t)$ which were calculated with eqn. 5 and $N=2$, for five different flow functions. These were the constant flow, the sinusoidal flow, the pulsatile flow with constant amplitude and pulsatile flow with modulated amplitude for two frequencies of modulation. The $C_{N}(t)$ curves calculated were converted into an analogue signal and recorded on tape. These recordings were led to the differentiator and analysed with the procedure described above (filter frequency $5 \mathrm{~Hz}$ ). The results are presented in Fig. 1, which shows the input flow functions, the recorded analogue $C_{N}(t)$ curve and its derivative and the resulting $Q(t)$ functions. In the region where the $C_{N}(t)$ curve approximates the baseline, the amplitude of the noise level increases rapidly and in the vicinity of the top of the $C_{N}(t)$ curve, the analysis fails due to inaccuracies in the determination of $C_{1}(t)$. Except for these parts the $C_{N}(t)$ curve proves to be useful for determining the instantaneous flow. Modulation effects can be distinguished clearly and even the highfrequency parts of $Q(t)$ compare well with $F(t)$. From this analysis we conclude that instantaneous flow can be estimated except for parts of the curve near the top and where the curve is close to the baseline.

\subsection{Experiments}

For an analysis of time-dependent flow from measured $C(t)$ curves, we restricted ourselves to the useful part of the curve which is described in the theoretical test. The flow variations are expressed by the function $Q(t)$ which can be calculated from eqn. 11. When estimating the absolute flow, an extra measurement will be needed to determine the factor $V$ in eqn. 12, relating $Q(t)$ to $F(t)$. This can be done by comparing the mean value of $Q(t)$ and the mean flow derived from the area under the (flow-weighted) indicator-dilution curve (VON RETH, 1984). This is not done in the present analysis.

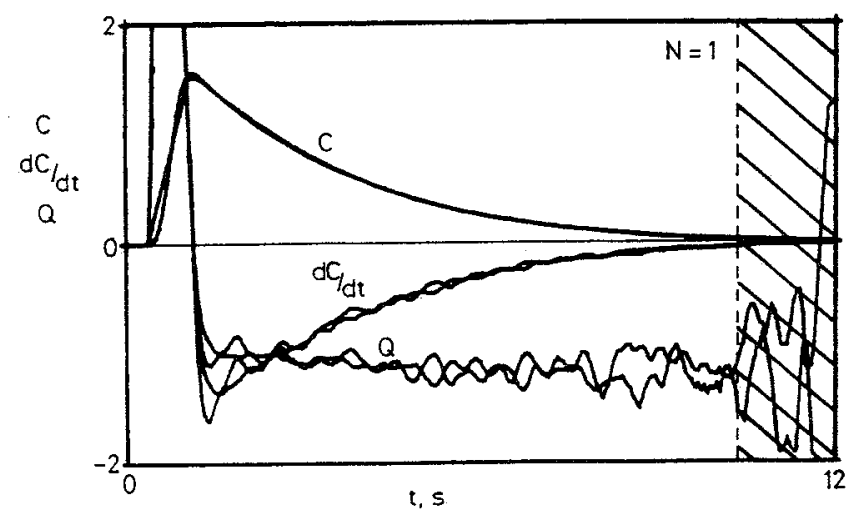

Fig. 2 Measured curves, derivatives and $Q(t)$ functions in a onecompartment system for constant flow for two successive injections of indicator 
Examples of the analysis with constant flow in a onecompartment system are given in Fig. 2. In this figure, the resulting curves, the derivatives and the calculated $Q(t)$ functions are plotted for two successive injections under identical conditions.

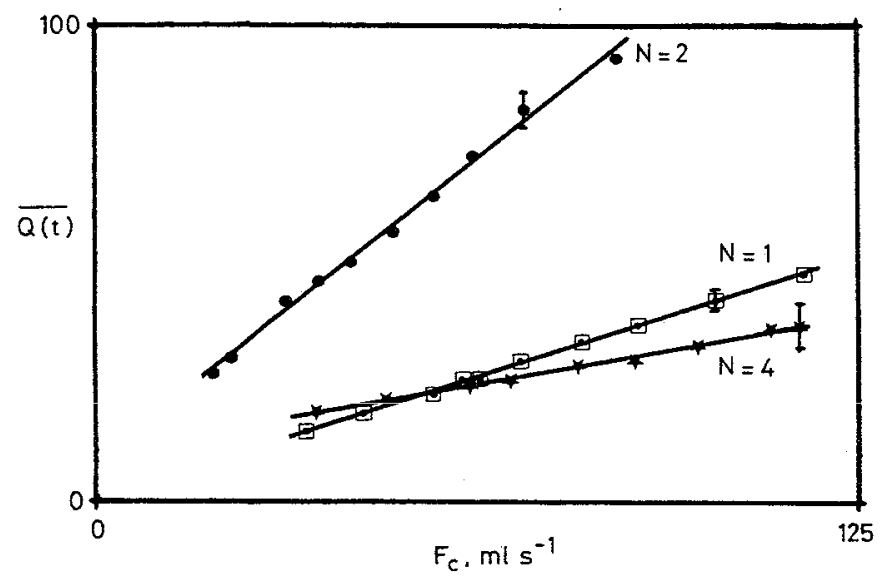

Fig. 3 Mean $Q(t)$ against flow $F_{c}$. Each data plot is the mean value of ten measurements. The standard deviations from the mean are shown with bars

The relationship between the adjusted flow $F_{c}$ and the mean value of $Q(t)$ in constant flow is represented graphically in Fig. 3 for a one-, two- and four-compartment system. The $\overline{Q(t)}$ value is linearly related to the flow. The intercept of the extrapolated best-fit line differs signifcantly from zero in the two- and four-compartment cases, suggesting a higher-order relationship near the origin. According to eqn. 12, the slope of the lines is equal to the volume of one ideal mixing chamber. The calculated total effective volume was approximately 15 per cent smaller than the geometrical volume of the system between the injection and sampling sites; this value varied with the type of mixing system.

One result of an experiment with sinusoidally varying flow is shown in Fig. 4 where the directly measured flow $F(t)$ is presented together with the corresponding indicator-dilution curve, its derivative and the calculated $Q(t)$ function.

The values of $Q_{m}$ proved to be independent of the frequency and amplitude of the variation and of the phase at the moment of injection. The relationship between $Q_{m}$ and
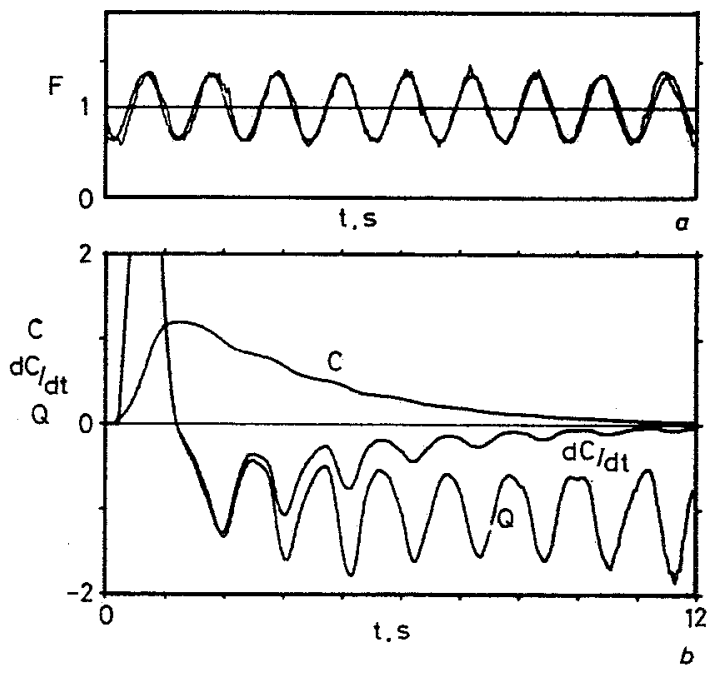

Fig. 4 Flow estimation in sinusoidally varying flow: (a) flow function; (b) indicator-dilution curve, derivative and $Q(t)$ function
$F_{m}$ is linear, analogous to the relationship found in the constant-flow experiments. The quotient $A_{q} / A$ depended on the values of the mean flow, the relative amplitude, the frequency and the volume of the mixing system. A dimensionless parameter $\xi$ was introduced, representing the quotient of the volume of the fluid that is transferred by the sinusoidal variations and the effective volume of the mixing system; it contained the flow parameters mentioned:

$$
\xi=\frac{2 \pi A F_{m}}{\omega N V}
$$

The results in the one-compartment case (Fig. 5) and also in the more-compartment systems show that beyond a certain $\xi$ value $(\xi>0.5)$, the ratio $A_{q} / A$ will converge on the expected value of unity.

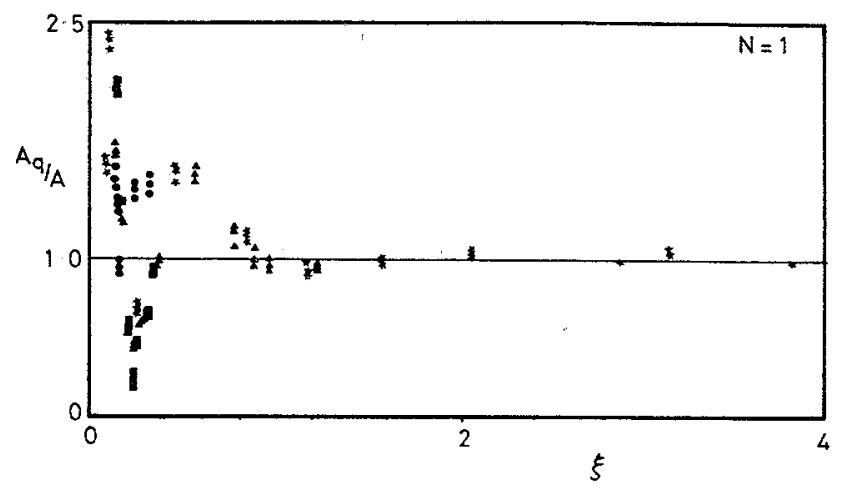

Fig. $5 A_{q} / A$ plotted against $\xi$ for the measurements in the one compartment for sinusoidally varying flow.

Varied parameters: $\mathbf{A}=F_{m}(V=108 \mathrm{ml})$

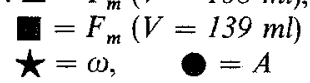

Finally, the feasibility of the method was studied using curves measured for pulsatile flow, both modulated and unmodulated. A typical result for unmodulated flow is shown in Fig. 6. The function $Q(t)$ shows a fluctuating pattern with the frequency of the pulsations, but the amplitude of the $Q(t)$ pulses is only constant over a rather small part of the $Q(t)$ curve. Experiments were performed with different amplitudes of $F(t)$ from which it was concluded that the mean of $Q(t)$, for the useful part of the $Q(t)$ curve, shows a linear relationship with the mean of $F(t)$. However, in modulated pulsatile flow the modulation could not be distinguished because there were only a few $Q(t)$ beats in the relevant part of the curve.

\section{Discussion}

Based on the ideal mixing chamber model a procedure was developed to derive information on momentary flow from an indicator-dilution curve obtained after a bolus injection of indicator. CROPP and BURTON (1966) reported a procedure, estimating instantaneous flow from the recording of the reciprocal of a constant-infusion indicator-dilution curve, with restrictions for the distance between injection and detection points. Their analysis was not applicable to the bolus-injection method. CAssot et al. (1978) indicated that, with their description of indicatordilution curves, based on a dispersion theory, evaluation of flow dynamics might be possible.

Our analysis is based on the $N$-compartment model and comprises analogue differentiation of the measured curve and numerical deduction of the virtual indicator-dilution curve behind the first mixing chamber. Theoretically, the 
procedure was tested for various flow.functions. Except for some parts at the vicinity of the top and near the baseline, the indicator-dilution curve proved suitable for the flow analysis.
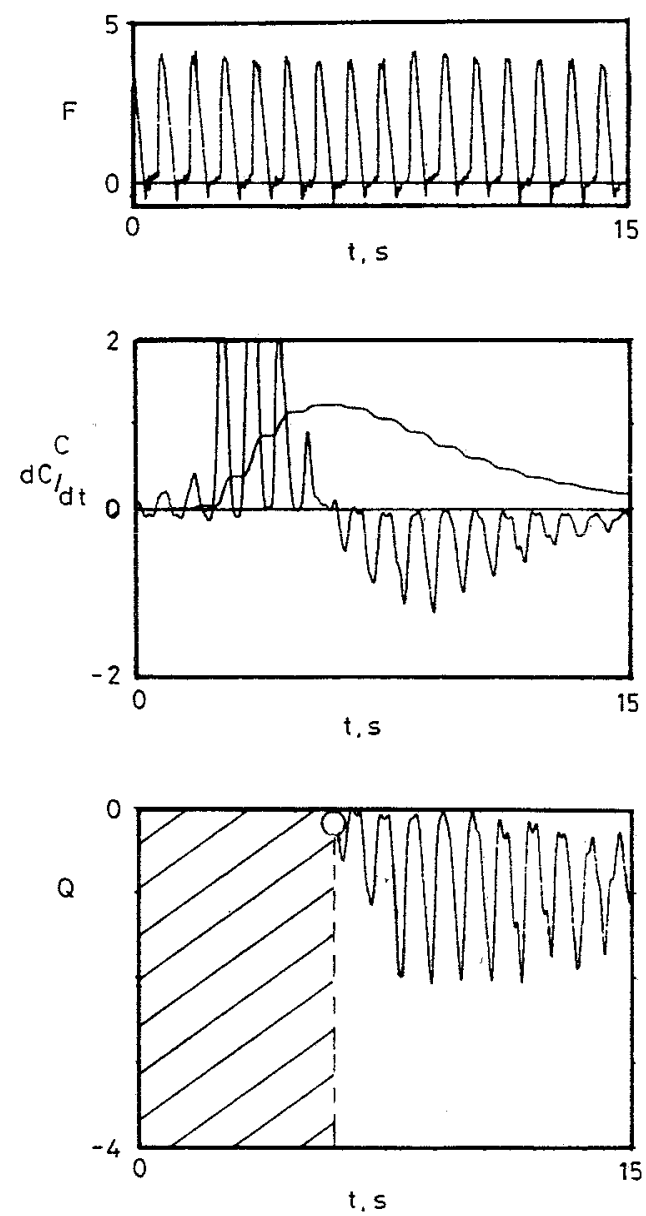

Fig. 6 Analysis of a curve measured in an unmodulated pulsating flow of a physical flow system. Only the descending limb is used

The results in a constant flow setup showed a linear relationship between $\overline{Q(t)}$ and $F_{c}$ in the one-compartment system. For the two- and four-compartment curves an intercept was observed when linear regression was applied, for which theory does not account. This may be caused by more and more asymmetrical curves when the flow decreases, which implies that for decreasing flow the number of compartments describing the mixing system tends to unity. This leads to nonlinearity in the relationship for small flow values.

Measurements in sinusoidal flows with both highfrequency and low-frequency variations with respect to indicator passage time were performed. From these measurements it can be concluded that frequency and phase of the flow can be derived accurately from $Q(t)$. According to the measurements for constant flow, $Q_{m}$ is related to $F_{m}$ linearly and is not dependent on other flow parameters. The parameter $A_{q}$ is linearly related to $A$, but the quotient $A_{q} / A$, however, depends on the mean flow value, the frequency of variation and on the volume of the mixing system. This is expressed by the relationship of $A_{q} / A$ with $\xi$.

Testing the analysis in a physical model with pulsating flow showed the limitations of this procedure: for highfrequency pulsations associated with small $\xi$ values, the amplitude could be miscalculated, as is shown in Fig. 5. For low-frequency pulsations, the amplitude is fairly accurate, but only a few pulsations will occur during the passage of a curve when the values of flow and mixing parameters are chosen in accordance with physiological data. Furthermore, the position of the baseline seemed to be of great influence. This effect is illustrated in Fig. 7, where a theoretical indicator-dilution curve for constant flow is plotted with its analytically determined derivative and $Q(t)$ function. In the situation marked ${ }_{1}$ the baseline of the indicator-dilution curve is zero and $Q_{1}(t)$ is a straight line representing the constant flow. In situation ${ }_{2}$ the curve is offset by 2 per cent of the maximum value. The shift in the $C(t)$ curve is barely visible and its derivative is identical to the one in ${ }_{1}$. Function $Q_{2}(t)$ is constant and equal to $Q_{1}(t)$ for the first part of the curve, but it deviates increasingly in the descending part.

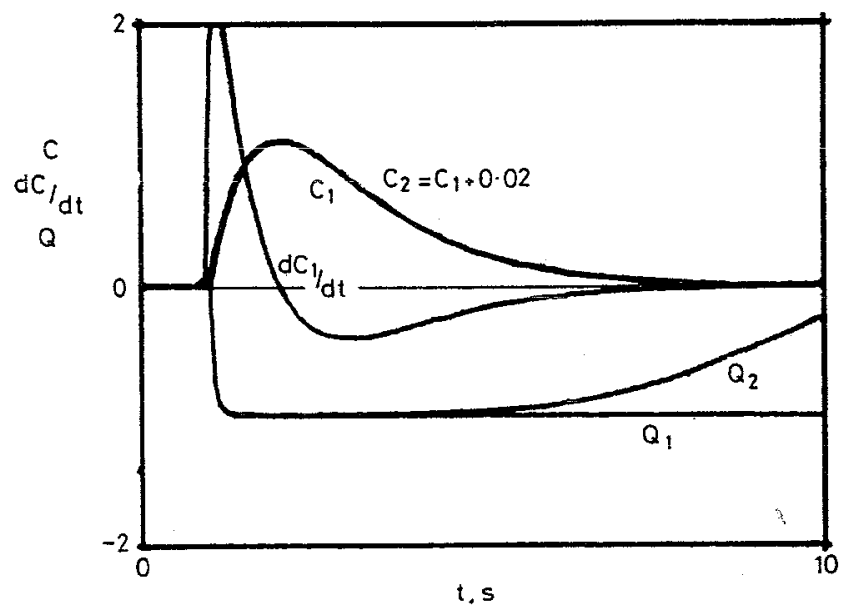

Fig. 7 Effect of baseline offset on $Q(t)$

In conclusion, it is stated that the analysis of instantaneous flow holds for the constant flow case and, with restrictions, for the sinusoidal flow case. In pulsatile flow, the results for the unmodulated case are promising. The proposed analysis should be developed and tested in more detail and, furthermore, an evaluation in the in vivo practice is needed. Attention must be given to the time constant of the indicator measuring device which must be sufficiently small to allow for the measurement of highfrequency flow variations via the indicator-dilution curve.

\section{References}

Bassingthwaighte, J. B., Knopp, T. J. and Anderson, D. U. (1970) Flow estimation by indicator dilution (bolus injection): reduction of errors due to time-averaged sampling during unsteady flow. Circ. Res., 27, 277-291.

Branthwaite, $M$. and BRADley, R. (1968) Measurement of cardiac output by thermal dilution in man. J. Appl. Physiol., 24, 434-438.

Cassot, F., SaAdian, A. and MCKay, C. (1978) Heat and mass transfer of a thermal indicator in pulsatile flow through the cardio-pulmonary system: II. Identification of cardiac output. Med. Progr. Technol., 5, 215-222.

Cropp, G. J. A. and Burton, A. C. (1966) Theoretical considerations and model experiments of the validity of indicator dilution methods for measurement of variable flow. Circ. Res., 18, $26-47$.

JanSEN, J. R. C., BogaARd, J. M., von Reth, E. A., SCHreuder, J. J. and Versprille, A. (1979) Monitoring of the cyclic modulation of cardiac output during artificial ventilation. Proc. 1st Int. Symp. Comput. Critical Care Pulmonary Med., Norwalk, Connecticut, 24th-26th May 1979, 59-68.

JANSEN, J. R. C., SCHREUDER, J. J., BogaARd, J. M., VAN RoOIJeN, W. and Versprille, A. (1981) Thermodilution technique for measurement of cardiac output during artificial ventilation. $J$. Appl. Physiol: Respirat. Environ. Exercise Physiol., 50, 584-591. 
JARLøV, A. and MYGIND, T. (1979) Ventricular volumes determined from indicator dilution curves. Med. \& Biol. Eng. \& Comput., 17, 31-37.

JARLøV, A. and LARSEN, B. (1981) Stroke volumes and ventricular volumes determined from indicator-dilution curves, Part 1. Ibid., 19, 457-460.

Silove, E. D., Gantez, T. and Wells, B. C. (1971) Thermodilution measurement of left and right ventricular outputs. Cardiovasc, Res., 5, 174-177.

Schlossmacher, E. L., Weinstein, H., Lochaya, S. and SchafFER, A. B. (1967) Perfect mixers in series model for fitting venoarterial indicator-dilution curves. J. Appl. Physiol., 22, 327-332.

SNYDER, J. V. and POWNER, D. J. (1982) Effect of mechanical ventilation on the measurement of cardiac output by thermodilution. Crit. Care Med., 10, 677-682.

ValentinuzZi, M., Valentinuzzi, M. E. and PosCY, J. A. (1972) Fast estimation of the dilution-curve area by a procedure based on a compartmental hypothesis. J. Ass. Adv. Med. Instr., 6, 335-343.

von Reth, E. A. and BogaARd, J. M. (1983) Comparison of a two-compartment model and distributed models for indicatordilution studies. Med. \& Biol. Eng. \& Comput., 21, 453-459.

von Reth, E. A., Aerts, J. C. J., van Steenhoven, A. A. and VERSPRILLE, A. (1983) Model studies on the influence of nonstationary flow on the mean flow estimate with the indicatordilution technique. $J$. Biomech. 16, 625-633.

VON RETH, E. A. (1984) Assessment of the indicator-dilution technique in nonstationary flow. Diss. Abstr. Int., section $C$; thesis Eindhoven University of Technology, Eindhoven, The Netherlands.

\section{Authors' biographies}

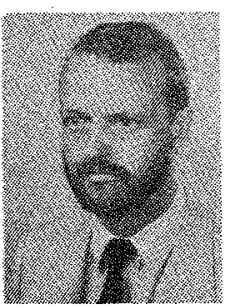

Dr Ir E. A. von Reth studied physics at the Eindhoven University of Technology and graduated in 1978. In 1983 he received his Ph.D. with a thesis 'Assessment of the indicator-dilution method in non-stationary flow'. At present he is working with Philips International BV, Medical Systems Division, in the application of new radiological methods and equipment in clinical practice.

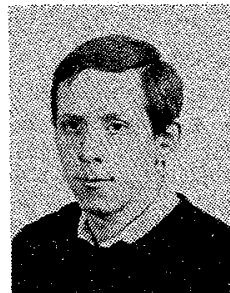

Ir M. J. F. P. Pluym studied physics at the Eindhoven University of Technology and obtained his degree in 1983. At present he is a doctoral candidate working on the development of an air velocity meter for very low velocities $\left(v \leqslant 5 \mathrm{~cm} \mathrm{~s}^{-1}\right)$.

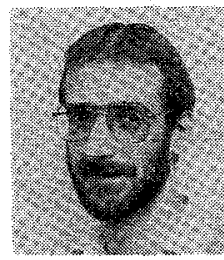

Dr Ir A. A. van Steenhoven received his Doctor of Engineering degree in 1979 from Eindhoven University of Technology, The Netherlands, where he is staff member in the department of Mechanical Engineering. His primary interest is the application of fluid dynamics on the cardiovascular system.

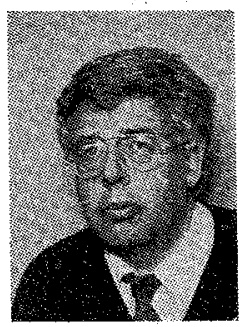

Professor J. A. Poulis is lecturer at the department of Physics of the Eindhoven University of Technology. His research area is the analysis of physical measuring methods, especially in the biomedical field.

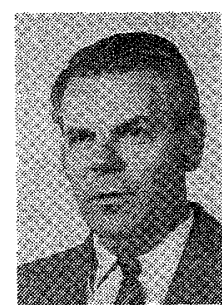

Professor A. Versprille is a full professor in clinical respiratory physiology and head of the research laboratory of the Department of Pulmonary Diseases, Erasmus University, Rotterdam and head of the pulmonary laboratory, University Hospital 'Dijkzigt'. The field of mechanical ventilation and the development of diagnostic and therapeutic methods as a spinoff of this basic reserach are his main interests. 